\title{
EDITORIAL
}

\section{A RIDPHE DE “L” A “R”: DISCUTIR E DIFUNDIR}

Maria Cristina Menezes

Faculdade de Educação/UNICAMP

menezes.mariacristina@gmail.com

A RIDPHE_R Revista Iberoamericana do Patrimônio Histórico-Educativo entra no ar como espaço de divulgação dos estudos, pesquisas, discussões, sobre o Patrimônio HistóricoEducativo dos Investigadores e grupos que se ocupam com os temas que são difundidos, em especial através da Ridphe_l, lista de discussão da Rede Iberoamericana para a investigação e a Difusão do Patrimônio Histórico-Educativo. Os Simpósios Iberoamericanos: História, Educação, Patrimônio-Educativo, que neste ano de 2015 tiveram a sua $4^{\mathrm{a}}$ versão, têm se desenvolvido desde 2012, quando do I Simpósio Iberoamericano que se realizou na Faculdade de Educação da UNICAMP, em Campinas/São Paulo, no Brasil; em 2013 houve o II Simpósio Iberoamericano em Buenos Aires/Argentina; em 2014 o III Simpósio em Cuernavaca/Morelos, no México; em 2015 o IV Simpósio, em São Paulo/São Paulo/Brasil, e em 2016 se realizará o V Simpósio Iberoamericano: História, Educação, PatrimônioEducativo que terá a sua 5 $5^{\text {a }}$ versão em 2016 em San Sebastián, País Vasco, Espanha, na mesma ocasião em que se realizarão as VII Jornadas da SEPHE, Sociedad Española para el Estudio del Património Histórico-Educativo.

No I Simpósio Iberoamericano, em Campinas, já se havia enunciado a necessidade de um canal de divulgação das pesquisas, estudos e seus resultados que se articulasse à RIDPHE, aos temas que a sustentam e se produzem como resultado de interlocuções sobre a investigação e a difusão do patrimônio histórico-educativo. Foi nesse âmbito que emergiu o projeto da criação de uma revista virtual, que pudesse divulgar as pesquisas sobre o tema do Patrimônio Histórico Educativo, da qual a responsabilidade recaiu naquele momento sobre a Ridphe_l, e em especial de que se articulasse a uma Universidade com suporte para tal. A lista de discussão Ridphe_1 desde 2008 tem sido gerenciada e moderada através da UNICAMP, que lhe dá o necessário suporte. Ao se verificar a possibilidade de a Revista ser hospedada no Portal de Publicações Periódicas Eletrônicas da Faculdade de Educação, da UNICAMP, isso também se confirmou. O tema foi retomado nas deliberações finais do III Simpósio Iberoamericano: História, Educação, Patrimônio-Educativo, no México, quando se colocou a importância de um veículo de divulgação virtual das pesquisas realizadas pelos investigadores que se ocupam com o tema do patrimônio histórico-educativo, em nível iberoamericano. 
Finalizado o IV Simpósio Iberoamericano em São Paulo/2015, a organização da Revista não mais se havia de prorrogar, uma vez que a divulgação de textos discutidos nos Simpósios, cuja organização se restringe a um máximo de 40 trabalhos, tendo a participação de todos em todas as apresentações de comunicação, com posterior discussão por todo o grupo de investigadores presente, também se coloca. A Revista, para além dos Anais dos Simpósios, possibilita que sejam selecionados textos dos diversos eixos discutidos nos simpósios para divulgação mais ampla dando visibilidades às pesquisas e seus resultados, sobretudo, em nível Iberoamericano, sendo também aberta aos trabalhos de investigadores do Patrimônio Histórico-Educativo de outros países/regiões, desde que enviados em português ou espanhol.

A Revista RIDPHE_R, ISSN: 2447-746X contará com edição semestral. Nesta Primeira Edição, v. 1, n.1, que é apresentada como EDIÇÃO INAUGURAL, traz um rol de artigos que congrega em seu espaço investigadores espanhóis, do País Vasco e de Sevilha, da Argentina, do México, brasileiros de diferentes estados do país, Santa Catarina, Minas Gerais, Bahia, Rondônia, São Paulo. Os artigos desta Edição Inaugural foram divididos em blocos temáticos que congregam investigadores destes diferentes países e ou estados do Brasil.

O primeiro bloco temático, que compõe a seção de artigos da Edição Inaugural da RIDPHE_R, centra-se no tema dos cadernos, neste espaço dividido por cadernos escolares de alunos e cadernos pessoais de um professor. No texto "La construcción de la identidad nacional a través de los cuadernos escolares en el franquismo en el País Vasco" os autores Paulí Dávila Balsera, Luis Maria Naya Garmendia iniciam a edição com a discussão sobre os cadernos escolares de alunos, que abordam como espaço de resistência, em contraposição ao que usualmente se apresenta sobre esse dispositivo escolar alinhando-o ao currículo prescrito. Os cadernos estudados pelos autores compõem o fundo de cadernos do "Museo de La Educación”, da Universidade do País Vasco, criado por iniciativa dos autores. Também sobre cadernos, porém de professores, debruça-se a investigadora Maria Teresa Santos Cunha, da UDESC/SC, no artigo "Viver e escrever: história e educação no acervo de cadernos de um professor catarinense (século XX)" sobre uma das coleções de cadernos que compõe o Acervo de Cadernos do Laboratório de Patrimônio Cultural (LABPAC) da UDESC. O estudo em questão traz o conjunto de 45 cadernos pessoais deixados por um professor e intelectual catarinense, antigo docente da UDESC. 
O segundo bloco da seção de artigos traz a discussão sobre os métodos de leitura que foram reconhecidos em uma série de manuais escolares encontrados na biblioteca escolar sob a guarda da Universidade Autónoma del Estado de Morelos, no México. São manuais que serviram ao ensino da leitura e da escrita e sobre os quais discorre a investigadora mexicana Lucia Martinez Moctezuma em seu artigo "Los manuales de lectura, un patrimonio de la historia educativa de mexico". Neste mesmo bloco Francisca Izabel Pereira Maciel, da Faculdade de Educação - Universidade Federal de Minas Gerais/UFMG e Kátia Gardênia Henrique da Rocha, da Universidade Federal de Ouro Preto, no texto "Hygino Amanajás e sua produção de livros de leituras escolares para o ensino primário: fragmentos da história da leitura no Pará" perseguem a história da leitura no estado do Pará através dos livros escolares escritos por um autor paraense, figura política com atuação no campo educacional.

O bloco que segue, bloco três, se insere no âmbito da museologia da educação ao buscar configurar a composição e a difusão possível em museus escolares, tal como propõe a Prof.a Maria Cristina Linares, estudiosa dos museus escolares e curadora do Museo de Las Escuelas de Buenos Aires, na Argentina, em "La pedagogía de la imagen: las láminas escolares como recurso histórico y museográfico en la historia de la educación". A apresentação do texto da Prof.a Linares se mostra muito elucidativo, uma vez que se detém sobre uma das coleções que compõe o Museo, a coleção das lâminas Escolares, que serão exploradas na potencialidade para o estudo da cultura escolar, como também de guardar e expor os materiais nos museus de educação. No mesmo bloco, Christine Müller em "Educação em museus: a interação como experiência" busca trazer as considerações de estudo realizado sobre a educação nos museus, em uma discussão atual e provocativa ao investir em vertente que aposta nesta educação em uma versão que se aproxima da interação quando a mesma traz apresenta de forma interativa com o público.

No quarto bloco os textos apresentados incidem sobre a utilização do conteúdo digital como fonte de investigação para os estudos e pesquisas acadêmicas. Os autores David Antonio da Costa, da Universidade Federal de Santa Catarina/UFSC e Wagner Rodrigues Valente, da Universidade Federal de São Paulo/UNIFESP, apresentam o texto "O repositório de conteúdo digital nas pesquisas de história da educação matemática” que traz a organização de um repositório de conteúdo digital, cujo espaço virtual abriga digitalizações de documentos utilizados nas pesquisas dos participantes do grupo de pesquisa em Educação Matemática, sob a coordenação de Wagner Valente. O repositório visa o compartilhamento de fontes aos participantes das várias regiões do Brasil. O artigo "Redes sociais virtuais: territórios abertos 
para a história da educação" de Robson Fonseca Simões, da Universidade Federal de Rondônia/UNIR, que compõe esse mesmo bloco investe nos escritos de ex-alunos do Colégio Pedro II, do Rio de Janeiro, agregados em uma comunidade organizada no Orkut. O autor buscou examinar esses escritos virtuais e as possibilidades que apresentam para os estudos em história da educação, sobretudo, ao interrogar como os sujeitos se colocam nestes escritos.

Destaque ao bloco cinco, quando Valeriano Durán Manso, da Universidade de Sevilha, no artigo "Los niños prodigio del cine español: aproximación a la educación de los años 50 y 60 " focaliza as crianças prodígios que ocuparam as telas do cinema nos anos 50 e 60, do século XX, na Espanha. Essas películas, vistas como patrimônio histórico e educativo, guardam a memória de um cine com pretensão à educação, em que as telas serviam à propaganda cívica patriótica do Regime franquista.

No bloco de número seis, Carmen Sylvia Vidigal Moraes, Doris Accioly e Silva, Eliza dos Santos e Tatiana da Silva Calsavara, da Faculdade de Educação da Universidade de São Paulo, São Paulo, em "Reverberações de um arquivo escolar anarquista" trazem a discussão sobre os 10 anos da pesquisa realizada Centro de Memória da Educação, da USP, sobre o arquivo do educador anarquista João Penteado. O trabalho que apresentam se detém primeiramente sobre o inventário das fontes documentais que consideram em sua importância para o estudo da escola no Brasil e, em segundo momento, visam discutir as teorias e práticas anarquistas na educação iberoamericana. Também preocupadas com o levantamento e a catalogação de fontes importantes para a história da educação, em especial, à história da educação baiana, em "Missões de pesquisa: inventariando a documentação escolar do sertão baiano" as autoras Vânia Muniz dos Santos e Antonieta Miguel, da Universidade do Estado da Bahia, discutem o trabalho que realizam com a intenção de viabilizar inventário e banco de dados sobre essas fontes que se encontram dispersas pelo interior baiano.

Em último bloco de artigos, Maria Cristina Menezes e Maria de Lourdes Pinheiro, no texto "Organização da biblioteca da Escola Normal de Campinas - o mapeamento das coleções pedagógicas (1930-1960) nos apontamentos de uma pesquisa" avaliam aspectos de uma investigação em desenvolvimento no âmbito de projeto maior. O subprojeto, que abordam no artigo apresentado, traz as coleções pedagógicas que compõem a biblioteca pedagógica da antiga instituição de Campinas para a discussão de procedimentos adotados de descrição e investigação dessas fontes. 
A revista se compõe de editorial, seção de artigos, seção de resenha e seção de documentos, em que se busca publicar documentos que se constituem em fontes importantes para as pesquisas em educação, em seus diferentes suportes.

Na seção Resenhas desta edição, Letícia Vieira, da FEUSP, em "Reinvenções de si: acervos pessoais e o uso de escritas ordinárias como fontes para produção histórica" resenha o belo livro escrito por Maria Teresa Santos Cunha e Flávia de Freitas Souza “ Viver e escrever: cadernos de escritas ordinárias de um professor catarinense (Sec. XX)", publicado em Florianópolis, pela Editora Insular, em 2015.

Na seção Documentos Silvia Regina Cason, do CIVILIS/FE/UNICAMP, apresenta o estudo intitulado "As conferências do curso para professores do Barão Degerando - 1839", sobre o texto publicado no Brasil em 1839 - Curso Normal Para Professores de $1^{a}$ s letras ou Direções Relativas a Educação Physica, Moral e intelectual. Nas Escolas Primárias - Pelo Barão Degerando - Impresso por ordem do Governo Provincial do Rio de Janeiro. Para uso dos Professores, Traduzido e acrescentado com um apêndice de Leis Gerais e Provinciais Sobre escolas. pelo Dr. João Candido de Deos e Silva. Nictheroy. Typographia Nictheroy de M.G. de S. Rego, Praça Municipal-1839; 421 páginas.

O texto, que foi utilizado no Brasil por largo período, tem pouca divulgação entre os estudiosos da história da educação e pouquíssima penetração enquanto documento. A autora revela que o seu primeiro contato foi com o microfilme que havia sido adquirido pela orientadora na Biblioteca Nacional, Rio de Janeiro. Informa que ao investir na pesquisa sobre o mesmo, por sorte, houve a possibilidade de realização de cópia em CD-Rom, o que em muito lhe facilitou o estudo.

A seção Notícias dessa Edição anuncia o V Simpósio Iberoamericano: História, Educação, Patrimônio-Educativo, e as VII Jornadas da SEPHE, Sociedad Española para el Estúdio del Património Histórico-Educativo, que acontecerão conjuntamente em 2016, em San Sebástian/Donostia, País Vasco, Espanha, que em 2016 será a capital cultural da Europa.

Com os votos de boa leitura a todos e no aguardo de que esta seja a primeira edição de muitas outras que virão com a contribuição de investigadores iberoamericanos do patrimônio histórico educativo, em especial, aqueles que se encontram articulados à RIDPHE e trazem em suas investigações a preocupação com os temas divulgados pela REDE. 
A Rede Iberoamericana para a Investigação e a Difusão do Patrimônio HistóricoEducativo permanece aberta a todos os investigadores que se ocupam de alguma forma com o Patrimônio Histórico-Educativo em trabalhos de preservação e organização de fontes com investigações que abordem estas fontes problematizando-as em seus estudos. Se a RIDPHE_R, Revista Iberoamericana do Patrimônio Histórico-Educativo se constitui em canal privilegiado de difusão dos resultados de estudos e pesquisas, sobre o Patrimônio HistóricoEducativo, dos Investigadores e grupos que se ocupam com essa temática, a RIDPHE-L, lista de discussão da RIDPHE constitui-se em canal privilegiado de discussão e divulgação dos eventos na área, em especial, do Simpósio Iberoamericano: História, Educação, PatrimônioEducativo e os seus resultados. Neste contexto a RIDPHE_L e a RIDPHE_R constituem-se em canal privilegiado aos investigadores da RIDPHE, Rede Iberoamericana para a Investigação e a Difusão do Patrimônio Histórico-Educativo.

Endereço para solicitar a inscrição na lista Ridphe-1:

ridphe 1-subscribe@listas.unicamp.br 